\title{
Technologiczna próba spawalności według ABV - SEP 1390
}

\author{
Weld bead bend test acc. to ABV-SEP 1390
}

\section{Streszczenie}

W artykule opisano technologiczną próbę spawalności stali konstrukcyjnych według wymagań SEP 1390. Omówiono zakres zastosowania próby, sposób pobierania próbek oraz techniczne aspekty przeprowadzenia próby i kryteria oceny. Na przykładzie badań własnych zobrazowano przypadki unieważnień oraz akceptacji wyników próby.

\section{Abstract}

The weld bead bend test acc. to ABV-SEP 1390 requirements for structural steels is presented in the paper. The weld bead bend test scope of use, sampling methods, technical aspects of it carrying out and evaluation criteria are discussed. Considering own test results, unaccepted and accepted test results are shown.

\section{Wstęp}

Spawalność jako zagadnienie techniczne pojawiło się w latach dwudziestych ub.w. wraz z wprowadzeniem spawania jako metody łączenia elementów konstrukcyjnych. W miarę rozwoju technik spawania oraz wprowadzania na rynek materiałów podstawowych o coraz wyższych właściwościach wytrzymałościowych zagadnienie spawalności nabrało szczególnego znaczenia w codziennej praktyce spawalniczej. Rozpatrując spawalność stali, należy zwrócić uwagę na te czynniki, które mogą wpłynąć na kruche pękanie przy spawaniu, a tym samym pozwolą ustalić optymalne parametry, które w najmniejszym stopniu wpływają na to zjawisko [1].

O złożoności zagadnienia spawalności mogą świadczyć różnorakie jej definicje, zawierające niekiedy zawiłą formę i ogólnikowe treści, jak również dziesiątki prób spawalności, stosowane przy jej określaniu.

Poniżej przytoczono definicję spawalności, opracowaną przez Międzynarodowy Instytut Spawalnictwa (MIS) i przyjętą przez Międzynarodową Organizację Normalizacyjną (ISO), według której uważa się, że materiał metaliczny jest spawalny $w$ danym stopniu, przy

Dr inż. Ryszard Pakos - Zachodniopomorski Uniwersytet Technologiczny w Szczecinie. użyciu danej metody spawania i $w$ danym przypadku zastosowania, gdy umożliwia, przy uwzględnieniu odpowiednich dla danego przypadku środków ostrożności, wykonanie złącza pomiędzy elementami łączonymi z zachowaniem ciągłości metalicznej oraz utworzenie złącza spawanego, które spełnia wymagania odbioru.

$\mathrm{Na}$ tej podstawie powstał najstarszy, stosowany na szeroką skalę podział, który wyróżnia [2]:

- spawalność metalurgiczną (związaną z właściwościami użytych materiałów, zależną od składu chemicznego i mikrostruktury stali, zawartości gazów i wtrąceń niemetalicznych itp.);

- spawalność konstrukcyjną (wynikającą z rodzaju konstrukcji spawanej i jej sztywności, rodzaju i przekroju spoin oraz łączonych elementów);

- spawalność operatywną - technologiczną (związaną z wybraną metodą spawania i zależną od warunków spawania, tj. natężenia prądu spawania, średnicy elektrody, prędkości spawania, techniki spawania, temperatury spawanego elementu);

- metody teoretyczne, dotyczące przede wszystkim spawalności lokalnej i mające na celu analizę przemian stali w procesie spawania oraz analizę właściwości materiału w strefie wpływu ciepła;

- metody praktyczne, obejmujące ogólne zagadnienia spawalności, w tym zjawisko pękania występujące w złączach spawanych w czasie procesu spawania, bezpośrednio po jego zakończeniu oraz w okresie następnych kilku dób (praktycznie 48 h). 


\section{Próba spawalności ABV-SEP 1390}

Próba spawalności przez zginanie napawanej płyty ma zastosowanie dla stali konstrukcyjnych o minimalnej granicy plastyczności $235 \div 355 \mathrm{~N} / \mathrm{mm}^{2}$ i grubości wyrobu min. $30 \mathrm{~mm}$. Celem przeprowadzonej próby jest sprawdzenie zdolności badanego materiału do pochłaniania pęknięć, przy czym sprawdza się, czy pęknięcie powierzchniowe powstałe w wykonanym stopiwie jest pochłaniane przy ciągłym naprężeniu przez strefę wpływu ciepła lub materiał podstawowy. Próbkę do badań należy poddać obróbce mechanicznej (rys. 1). Zaleca się, szczególnie w badaniach rozjemczych, używać tzw. próbek podłużnych. Niemniej jednak przepis dopuszcza stosowanie do badań próbek poprzecznych za zgodą klasyfikatora niezależnego nadzoru. Wymiary próbek oraz parametry techniczne gięcia przedstawiono w tablicy I. Próbę spawalności przez zginanie napawanej płyty wykonuje się $w$ temperaturze pokojowej.

Przygotowany zgodnie z rysunkiem 1 rowek należy wypełnić spoiwem przy następujących zaleceniach:

- metoda spawania: spawanie łukowe ręczne elektrodą otuloną (111),

- typ elektrody: elektroda rutylowa grubootulona (RR),

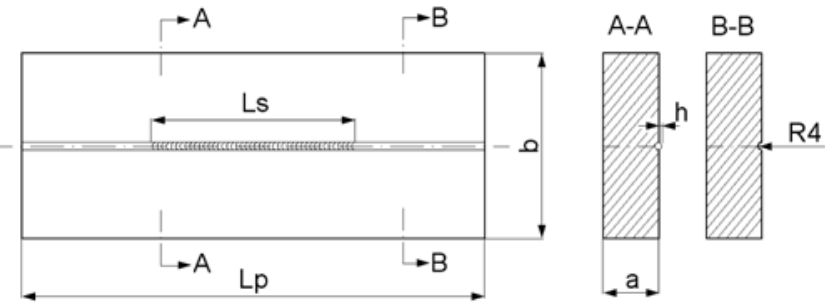

Rys. 1. Przygotowanie próbki do badań [4]: a - grubość próbki, $b$ - szerokość próbki, $L_{p}$ - długość próbki, $L_{s}$ - długość napawanego ściegu, $\mathrm{R}$ - promień rowka, $\mathrm{h}$ - nadlew napoiny

Fig. 1. Sample to weld bead bend test [4]: a - sample thickness, $b$ - sample width, $L_{p}$ - sample length, $L_{s}$ - pad welded bead length, $\mathrm{R}$ - groove radius, $\mathrm{h}$ - pad weld reinforcement
- średnica elektrody: $5 \mathrm{~mm}$,

- nadlew napoiny: ok. $1 \mathrm{~mm}$,

- długość ściegu zgodnie z tablicą I,

- parametry spawania: spawanie ciągłe bez przerw, ścieg nie podlega żadnej obróbce.

Wykonaną płytę próbną należy poddać próbie zginania zgodnie $z$ rysunkiem 2 , przy czym należy pamiętać, aby napawany ścieg leżał w strefie rozciągania.

Próba zostaje zakończona, gdy:

- próbka zostanie zerwana, lub

- zostanie osiągnięty kąt zgięcia min. $60^{\circ}$, mierzony na obciążonej próbce.

Próba spawalności zostanie uznana, jeżeli przynajmniej jedno powstałe pęknięcie w stopiwie zostanie zniwelowane przez strefę wpływu ciepła lub materiał rodzimy (podstawowy).

Próba nie będzie uznana, jeżeli próbka ulegnie złamaniu (zerwaniu) przed osiągnięciem kąta zgięcia $60^{\circ}$, ponadto nie zalicza się próby, gdy do momentu osiągnięcia kąta zginania $60^{\circ} \mathrm{w}$ stopiwie nie powstało pęknięcie powierzchniowe, które rozszerzyło się aż do linii wtopienia.

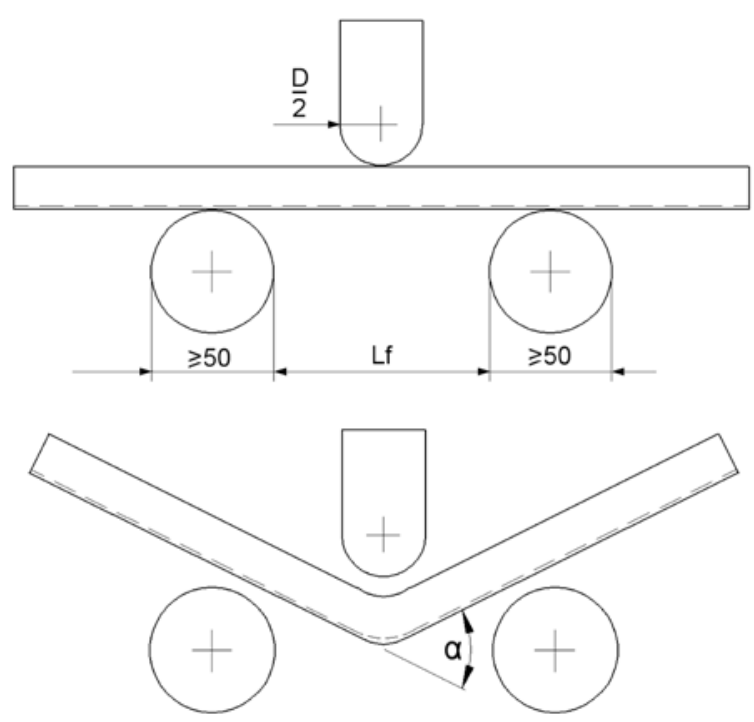

Rys. 2. Zginanie płyty próbnej [4]

Fig. 2. Weld bead bend test sample [4]

Tablica I. Wymiary próbek oraz parametry gięcia [4]

Table I. Dimensions of samples for weld bead bend test and bending parameters [4]

\begin{tabular}{|c|c|c|c|c|c|c|c|}
\hline \multirow{2}{*}{$\begin{array}{l}\text { Grubość nominalna } \\
\text { próbki, mm }\end{array}$} & \multicolumn{3}{|c|}{$\begin{array}{l}\text { Wymiary } \\
\text { próbek }\end{array}$} & \multirow{2}{*}{$\begin{array}{c}\text { Promień } \\
\text { rowka }\end{array}$} & \multirow{2}{*}{$\begin{array}{c}\text { Długość } \\
\text { ściegu } \\
\mathrm{L}_{\mathrm{s} \text { min }}, \mathrm{mm}\end{array}$} & \multicolumn{2}{|c|}{ Urządzenie zginające } \\
\hline & $\begin{array}{l}\text { długość, } L_{p} \\
\text { mm }\end{array}$ & $\begin{array}{c}\text { szerokość, b } \\
\mathrm{mm}\end{array}$ & $\begin{array}{c}\text { grubość, a } \\
\text { mm }\end{array}$ & & & $\begin{array}{c}\text { promień } \\
\text { trzpienia } \\
\text { gnącego, } \mathrm{mm}\end{array}$ & $\begin{array}{l}\text { odstęp między } \\
\text { wałkami } L_{f}, \mathrm{~mm}\end{array}$ \\
\hline$\geq 30$ do $\leq 35$ & 410 & 200 & \multirow{4}{*}{$\begin{array}{c}\text { możliwa } \\
\text { największa } \\
\text { grubość }\end{array}$} & 4 & 175 & 105 & 190 \\
\hline$>35$ do $\leq 40$ & 44 & 200 & & 4 & 190 & 120 & 220 \\
\hline$>40$ do $\leq 45$ & 470 & 200 & & 4 & 220 & 135 & 250 \\
\hline$>45$ do $\leq 50$ & 500 & 200 & & 4 & 220 & 150 & 280 \\
\hline$>50$ & 500 & 200 & 50 & 4 & 220 & 150 & 280 \\
\hline
\end{tabular}


Dla stali walcowanych termomechanicznie (TM) próbkę uważa się za zerwaną, jeśli odstęp pomiędzy środkiem ściegu a końcem pęknięcia jest większy niż 80 mm lub pęknięcie osiągnie krawędź próbki.

W przypadku niezaliczonej próby spawalności przez zginanie należy wykonać nową próbę na następnym wycinku próbnym tego samego wytopu lub na tym samym gatunku materiału z innego wytopu, przy czym zaleca się użycie w tym przypadku twardszej elektrody do napawania.

\section{Badania własne}

Celem badań własnych było przeprowadzenie próby spawalności przez zginanie napawanej próbki.
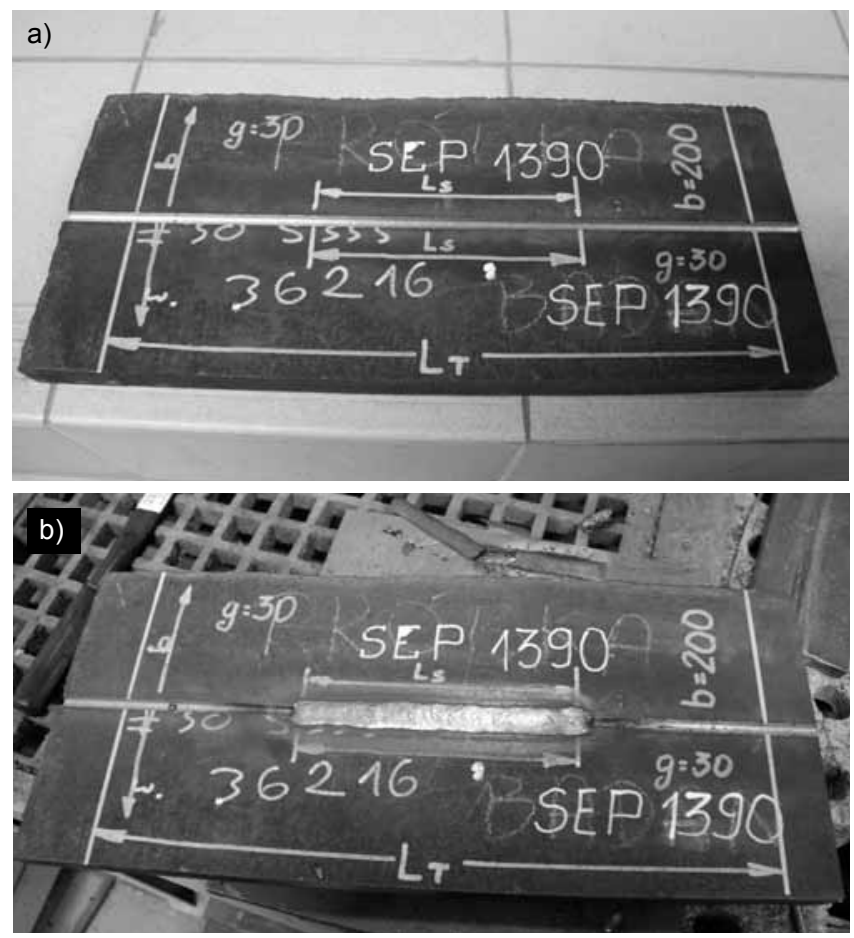

Rys. 3. Przygotowanie próbki do badań wytrzymałościowych: a) próbka po obróbce wiórowej, b) rowek wypełniony elektrodą otuloną

Fig. 3. Samples for mechanical properties test: a) sample after machining, b) weld groove filled in by MMAW method

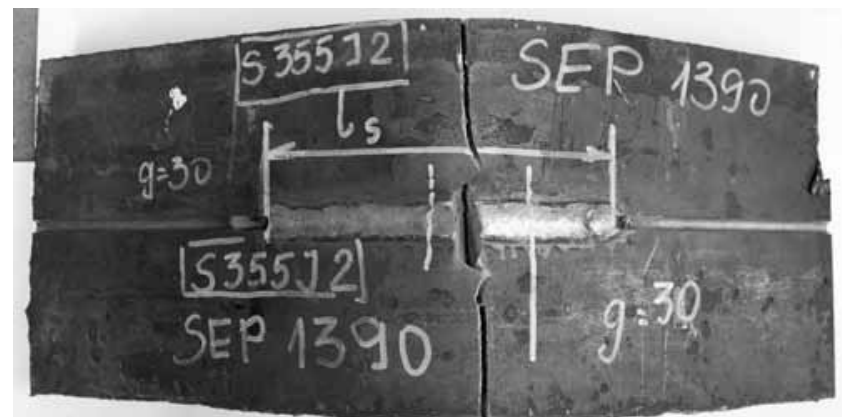

Rys. 4. Próbka nr 1 po próbie zginania (zerwanie)

Fig. 4. Sample no 1 after bending test (rapture)
Przedmiot badań:

- blacha S355J2+N $\quad \mathrm{g}=30 \mathrm{~mm}$ (próbka $\mathrm{nr} 1$ );

- blacha S355J3+N $\quad \mathrm{g}=50 \mathrm{~mm}$ (próbka $\mathrm{nr} 2$ );

- blacha S355JR $\quad \mathrm{g}=30 \mathrm{~mm}$ (próbka $\mathrm{nr} 3$ ).

Do wypełnienia rowka próbki zastosowano elektrodę grubootuloną E420RR o średnicy $5 \mathrm{~mm}$ (Elga-Maxeta 11). Parametry spawania przyjęto zgodnie z danymi katalogowymi producenta.

Przygotowanie próbki do badań przedstawiono na rysunku 3. Próbki, przygotowane tak jak pokazano na rysunku 3b, poddano próbie zginania na maszynie wytrzymałościowej o nacisku powyżej 100 t, przy zachowaniu parametrów próby zginania podanych w tablicy I. Wyniki badań zaprezentowano na rysunkach $4 \div 6$.

Przeprowadzone badania dały pozytywne wyniki (próba zaliczona) dla próbki nr 2 (S355J3+N, $\mathrm{g}=50 \mathrm{~mm}$ ) - stwierdzono dwa pęknięcia o długościach odpowiednio 2,2 i 1,1 mm wchodzące w głąb materiału rodzimego oraz dla próbki $\mathrm{nr} 3$ (S355JR, $\mathrm{g}=30 \mathrm{~mm}$ ) - jedno pęknięcie o długości $4 \mathrm{~mm}$ wchodzące w materiał rodzimy.

W przypadku próbki $\mathrm{nr} 1$ (S355J2+N, g = $30 \mathrm{~mm}$ ) uzyskano wynik negatywny (próba niezaliczona), gdyż nastąpiło zerwanie próbki przed osiągnięciem żądanego kąta zginania.

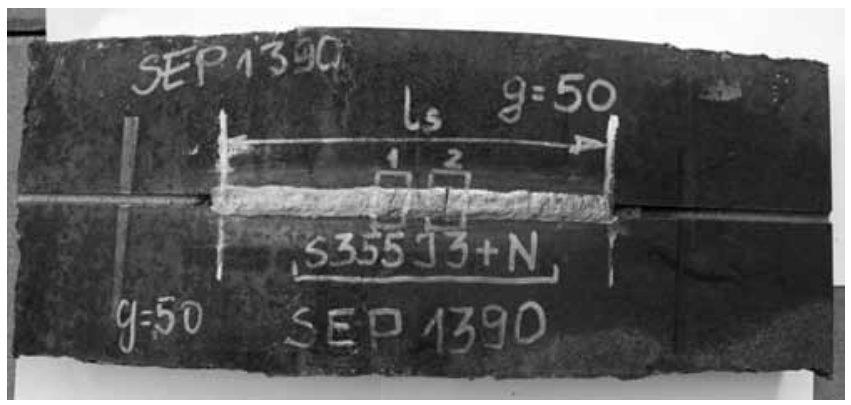

Rys. 5. Próbka nr 2 po zakończeniu próby

Fig. 5. Sample no 2 after bending test

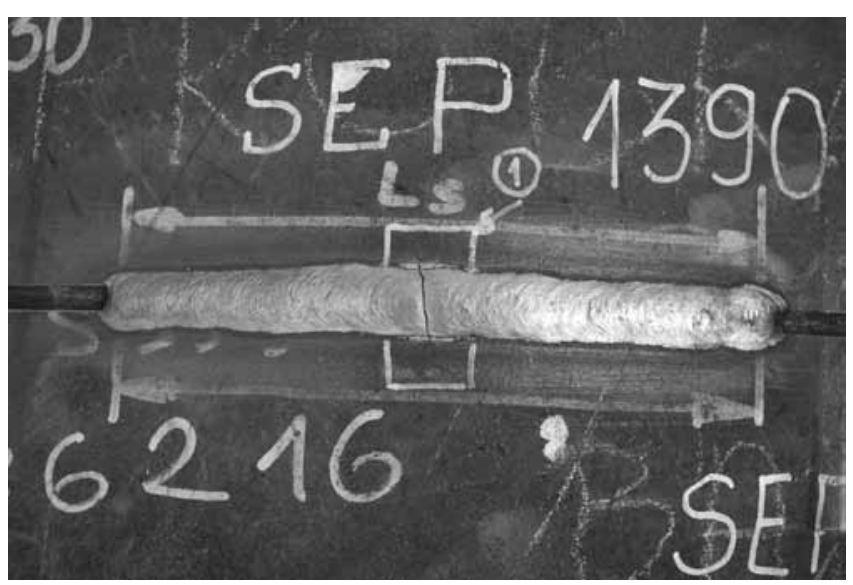

Rys. 6. Próbka nr 3 po zakończeniu próby

Fig. 6. Sample no 3 after bending test 


\section{Podsumowanie}

Próba spawalności wg ABV-SEP 1390 wykazała celowość określania zdolności badanego materiału do pochłaniania pęknięć. Należy zaznaczyć, że pomimo stosunkowo prostej procedury badania, można napotkać techniczne ograniczenia wykonania próby, związane z koniecznością posiadania prasy

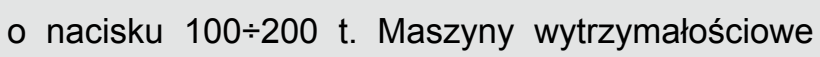
bądź prasy o nacisku mniejszym mogą nie zgiąć badanej próbki do wymaganego kąta. Należy pamiętać również o tym, że prezentowana próba spawalności ma zastosowanie do ograniczonej liczby gatunków stali konstrukcyjnych.

\section{Literatura}

[1] Butnicki S.: Spawalność i kruchość stali. WNT. Warszawa 1975.

[2] Pilarczyk J.: Poradnik inżyniera. Spawalnictwo t. 1. WTN. Warszawa 2003

[3] Łomozik M.: Metaloznawstwo i spawalność stali. Wydawnictwo Instytutu Spawalnictwa. Gliwice 1997.

[4] ABV - SEP 1390. 1996.

\section{Dolnośląska Sekcja Spawalnicza SIMP \\ Zakład Spawalnictwa Instytutu Technologii Maszyn i Automatyzacji i Wydział Mechaniczny Politechniki Wrocławskiej}

zapraszają do udziału

w 4. Międzynarodowej Konferencji Naukowo - Technicznej pod hasłem „POSTĘP W TECHNOLOGIACH LUTOWANIA” WROCŁAW 2013

Wrocław, 23-25 września 2013 (poniedziałek - środa) aula A1, bud. B-4 PWr, ul. Łukasiewicza 5

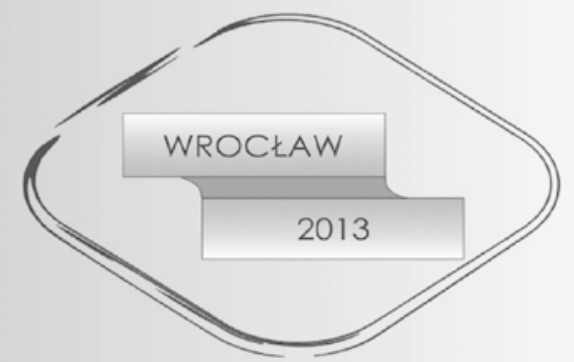

Wszystkich zainteresowanych udziałem w Konferencji prosimy o kontakt z Zakładem Spawalnictwa ITMiA Politechniki Wrocławskiej

Prof. dr hab. inż. dr h.c. Władysław Włosiński - Przewodniczący Komitetu Naukowego IV Wydział Nauk Technicznych PAN Warszawa

Prof. dr hab. inż. Andrzej Ambroziak - Sekretarz Komitetu Naukowego tel. (071) 3202148, e-mail: andrzej.ambroziak@pwr.wroc.pl

Prof. dr hab. inż. Zbigniew Mirski - Przewodniczący Komitetu Organizacyjnego tel. (071) 3202142, e-mail: zbigniew.mirski@pwr.wroc.pl

Mgr inż. Anna Woźna - Sekretarz Komitetu Organizacyjnego tel. (071) 3202074, e-mail: anna.wozna@pwr.wroc.pl

Dr inż. Tomasz Piwowarczyk - Sekretarz Komitetu Organizacyjnego tel. (071) 3204255, e-mail: tomasz.piwowarczyk@pwr.wroc.pl

Korespondencję prosimy kierować na adres:

Komitet Organizacyjny 4. Międzynarodowej Konferencji Naukowo - Technicznej „Postęp w technologiach lutowania”

Politechnika Wrocławska, Zakład Spawalnictwa ITMiA

Wybrzeże Wyspiańskiego 27

50-370 Wrocław 